\title{
A Juvenile Case of MELAS with T3271C Mitochondrial DNA Mutation
}

\author{
LAURA STENQVIST, ANDERS PAETAU, LEENA VALANNE, ANU SUOMALAINEN, \\ AND HELENA PIHKO
}

\begin{abstract}
Department of Neurology [L.S., A.S.], Biomedicum Helsinki, Helsinki University, FIN-00290 Helsinki, Finland; Department of Pathology [A.P.], Helsinki University, FIN-00014 Helsinki, Finland; Department of Radiology [L.V.], Helsinki University Central Hospital, FIN-00029 HUS, Finland; [L.P., H.P.], Hospital for children and adolescents, Helsinki University Central Hospital, FIN-00029 HUS, Finland
\end{abstract}

\begin{abstract}
We present here a patient with muscle fatigue and poor growth since the age of $6 \mathrm{y}$. The diagnosis of a mitochondrial disease was based on the presence of ragged red fibers in the muscle biopsy and on a combined defect of mitochondrial DNAencoded respiratory enzymes. Epilepsia partialis continua with stroke-like episodes appeared 2 mo before death at the age of 18 and prompted a search for mitochondrial DNA mutations associated with mitochondrial encephalopathy, lactic acidosis, and stroke-like episodes. Minisequencing of the patient's DNA samples revealed a heteroplasmic T3271C mutation with a 78-94\% mutation load in her fibroblasts or autopsy-derived tissue samples. This is the ninth reported non-Japanese patient with
\end{abstract}

\section{ABSTRACT}

T3271C mutation. Our patient shows that despite very high proportion of mutant mtDNA, the T3271C mutation can give rise to mild symptoms in childhood and to a rapid terminal phase that simulates encephalitis. (Pediatr Res 58: 258-262, 2005)

$\quad$ Abbreviations
MELAS, mitochondrial encephalomyopathy lactic acid
stroke-like episodes
MERRF, myoclonic epilepsy with ragged red fibers
MtDNA, mitochondrial DNA
RRF, ragged red fiber

MELAS (mitochondrial encephalomyopathy, lactic acidosis and stroke-like episodes) is the most common clinical entity caused by a mitochondrial DNA (mtDNA) mutation. It was first described in 1984 by Pavlakis, who reported two children and nine similar cases from the literature with normal early development; short stature; seizures; and alternating hemiparesis, hemianopia, or cortical blindness (1). Episodic headache with vomiting, hearing deficit, and slowly progressive dementia are frequent additional features. Suspicion of MELAS is often based on magnetic resonance imaging studies, which show infarct-like, often transient lesions that are not confined to vascular territories. Laminar cortical necrosis; focal necrotic, atrophic changes; and basal ganglia calcifications indicate an ongoing process rather than one ischemic incident. Increased amount of lactate is found in blood and cerebrospinal fluid in symptomatic patients, and ragged red fibers (RRF) are found in

Received September 8, 2004; accepted January 3, 2005.

Correspondence: Laura Stenqvist, M.D., Programme of Neurosciences, BiomedicumHelsinski, FIN-00290 Helsinki University, Haartmaninkatu 8, P.O. BOX 63, FIN-00290 Helsinki, Finland; e-mail:laura.stenqvist@hus.fi.

This study was supported by grants from the Alli Paasikivi Foundation and National Graduate School of Clinical Investigation (to L.S.) and the Academy of Finland and Sigrid Juselius Foundation (to A.S.).

DOI: 10.1203/01.PDR.0000169966.82325.1A muscle. Activities of mtDNA-encoded respiratory chain enzymes in the muscle, especially of complex I, are deficient.

At least 17 point mutations have been found in association with MELAS (MITOMAP, 2004), but only a few have been shown to be pathologic. Eighty percent of patients have an A to $\mathrm{G}$ transition at nucleotide position (np) 3243 in the mitochondrial tRNALeu gene corresponding to the UUR $(\mathrm{R}=\mathrm{A}$ or $\mathrm{G})$ leucine codons $(2,3)$. Another $7-15 \%$ of patients with MELAS have $\mathrm{T}$ to $\mathrm{C}$ transitions at np 3271 (T3271C) (4). The majority of the previously reported 20 patients with MELAS and the T3271C mutation have been Japanese (5-10). In the province of Northern Ostrobothnia in northern Finland, the prevalence of the A3243G mutation was found to be $>16.3: 100,000$ in the adult population (11). Chinnery et al. (12) studied the epidemiology of various mtDNA mutations in North East of England and found a 0.95:100,000 prevalence for the A3243G mutation in the adult population. The population frequency of the T3271C mutation has not been determined. In addition to classical MELAS, the A3243G mutation has been found in patients with progressive external ophthalmoplegia, Kearns-Sayre syndrome, deafness, and/or diabetes and in an overlap syndrome with features of MELAS and myoclonus epilepsy with ragged red fibers (MERRF) (13-18). 
Tarnopolsky et al. (4) reported six Caucasian patients with MELAS and the T3271C mutation and concluded that although the clinical courses were similar, the age of onset was later than in those with the A3243G mutation. The degree of heteroplasmy (i.e. the proportion of mutant versus wild-type mtDNA in the cell), the tissue distribution of mutant mtDNA, the threshold effect, and nuclear and mitochondrial DNA backgrounds are suggested to be the underlying factors associated with the clinical diversity of the A3243G mutation.

We report the clinical and pathologic findings in a patient with MELAS and the T3271C mutation. Her first clinical manifestations appeared at the age of $6 \mathrm{y}$, but she lived a normal life until the late teen years, when acute worsening of the disease led to her death at the age of only $18 \mathrm{y}$. We present here the biochemical and molecular genetic analysis of the autopsy samples of a rare Caucasian juvenile patient with MELAS and the T3271C mutation.

\section{METHODS}

All of the examinations and samples were taken with informed consent, according to the Declaration of Helsinki. The study was approved by the ethical committee of the Helsinki University Central Hospital.

Muscle biopsy, histochemistry, and ultrastructure. A muscle specimen was obtained from the vastus lateralis muscle by open biopsy under general anesthesia. Part of the muscle sample was immediately placed in ice-cold buffer with $0.25 \mathrm{M}$ sucrose, $2 \mathrm{mM}$ EDTA, $10 \mathrm{mM}$ Tris- $\mathrm{HCl}$, and $50 \mathrm{U} / \mathrm{mL}$ heparin ( $\mathrm{pH}$ 7.4) for biochemical analysis. Part of it was snap-frozen in liquid nitrogen for DNA analyses, part was frozen in isopentane cooled in liquid nitrogen for histologic and histochemical analysis, part was fixed in formaldehyde for paraffin sections, and part was fixed in glutaraldehyde for electron microscopy. The muscle was examined using hematoxylin-eosin, Van Gieson, modified Gomori trichrome, periodic acid-Schiff, oil red O, and myofibrillar adenosine triphosphatase ( $\mathrm{pH} 9.4,4.6$, and 4.3) stainings, and the histochemical activities of NADH-tetrazolium reductase and cytochrome oxidasesuccinate dehydrogenase were studied, as well as by electron microscopy (Jeol JEM 1200 EX electron microscope).

Biochemical and mtDNA analysis. Mitochondria were isolated from a fresh muscle biopsy specimen, and the respiratory chain enzyme activities $[\mathrm{CI}+\mathrm{II}$ (EC 1.6.5.3, EC1.3.5.1), $\mathrm{CI}+\mathrm{III}$ (EC1.6.5.3, EC1.10.2.2), CIV (EC1.9.3.1), CII, citrate synthase activity (EC2.3.3.1)] were analyzed within $4 \mathrm{~h}$ as previously described (19). Total cellular DNA was extracted from the muscle biopsy sample or fibroblasts derived from a skin biopsy sample, according to routine procedures.

Large rearrangements of mtDNA were analyzed by Southern blot analysis as described previously (20). Selected point mutations of mtDNA [A to G at the nucleotide 3243 or T to $\mathrm{C}$ at the nucleotide 3271 in tRNA Leu(UUR), an A to $\mathrm{T}$ transversion at the nucleotide 8344 of tRNALys] were analyzed by solid-phase minisequencing technique as described elsewhere (21). The blood leucocytes of the mother and two younger sisters of the patient were examined for $\mathrm{T} 3271 \mathrm{C}$ point mutation by solid-phase minisequencing, otherwise as the other mutations, but using the following primers: forward primer 5'agagcccggtaatcgcataa-3', reverse primer 3'-ggccatgggtatgttgttaaga-5', and detection primer 3 '-aattgaacctctgactgtaa-5'.

Paraffin embedded tissue samples and xylene treatment. The autopsyderived paraffin-embedded tissue samples from the patient were deparaffinized and amplified by PCR according to Shibata et al. (22).

\section{RESULTS}

Case history, examination, and pedigree. Our patient was born after an uneventful pregnancy at 36 wk gestation with birth weight of $2480 \mathrm{~g}$ and length $47 \mathrm{~cm}$. The parents and two younger sisters were healthy during the patient's lifetime, but diabetes was recently diagnosed in the 18-y-old younger sister (V-2), who is on insulin therapy. There is no other family history of diabetes. The maternal grandmother (III-2) had a psychiatric illness since the age of $27 \mathrm{y}$. She had diabetes and increasing headaches and was given the diagnosis of "organic schizophrenia, encephalopathy with cerebral atrophy" 2-3 y before her death, at the age of 42 y (Fig. 1).

The patient developed normally until the age of $6 \mathrm{y}$, when she was investigated because of poor growth and weight loss. Fatigue during exercise appeared at the age of $10 \mathrm{y}$. At $11 \mathrm{y}$ of age, she had palpitation during exercise, after which WolffParkinson-White syndrome and a cystic goitre with normal thyroid function was discovered. Some three- to five-beat supraventricular tachycardias without subjective sensations were seen in a 24-h Holter registration, but no changes in the ECG were recorded at the time when she complained of palpitation. The cardiac ultrasound was normal.

She was investigated by us at $12 \mathrm{y}$ of age. She attended normal school but had been unable to walk and attend school for 2 wk because of swelling of the ankles and fatigue. She was very thin with atrophic muscles, swollen ankles, and Achilles tendon tightness. She had no cardiomyopathy. Because her serum albumin value was also normal, the ankle swelling remained without explanation.

Her venous blood lactate level was up to $12.6 \mathrm{mmol} / \mathrm{L}$ (normal values $0.7-1.8 \mathrm{mmol} / \mathrm{L}$ ), pyruvate was $88-140$ $\mathrm{mmol} / \mathrm{L}$ (normal values $40-70 \mathrm{mmol} / \mathrm{L}$ ), and the liver transaminases were slightly elevated. Magnetic resonance imaging studies of her brain showed mild central and cortical atrophy (Fig. 2A).

At the age of $12 \mathrm{y}$, she started exercising to improve her condition, which provoked an acute episode of excessive fatigue and vomiting. On admission to the hospital, she was acidotic with blood lactate of $23.15 \mathrm{mmol} / \mathrm{L}$, blood $\mathrm{pH}$ of 6.9 , base excess of $-28.5 \mathrm{mmol} / \mathrm{L}$, and an extreme respiratory stress with arterial partial pressure of carbon dioxide of 1.9 $\mathrm{kPa}$. She developed bilateral pleural effusions and pneumothorax and was treated with ventilator support, pleural drains, hemodialysis, and blood pressure support with dopamine and i.v. infusions. After a short period of anuria and decreased gastric motility causing retention of the stomach, she started to

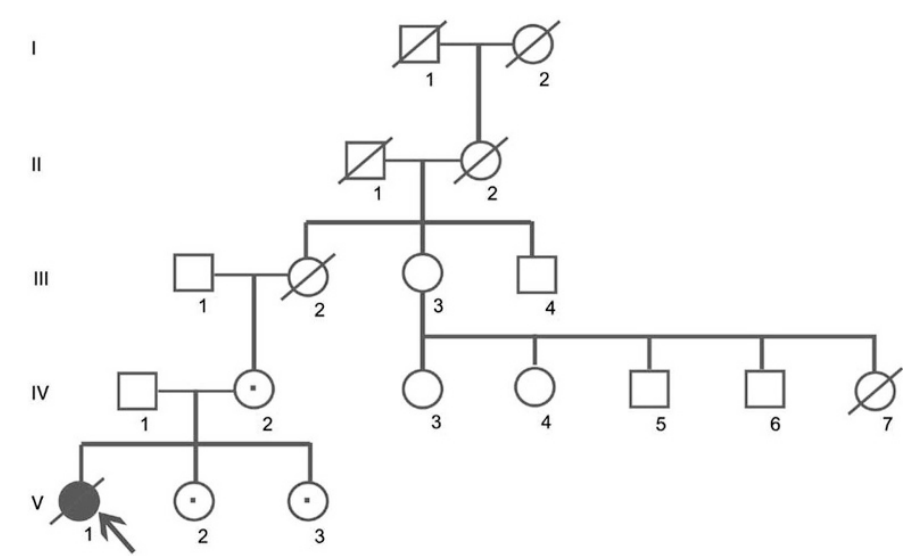

Figure 1. Family pedigree. The maternal grandmother (III-2) had diabetes and central atrophy of the brain and died at 42. The child (IV-7) of the maternal aunt died as a newborn because of structural cardiac disease. The patient's sister (V-2) developed diabetes at the age of 18; the other sister (V-3) is healthy. Arrow, index patient; filled symbols, affected individuals; open symbols, unaffected individuals; dotted symbols, carriers of the T3271C mutation. Numbers refer to generation and individual. 

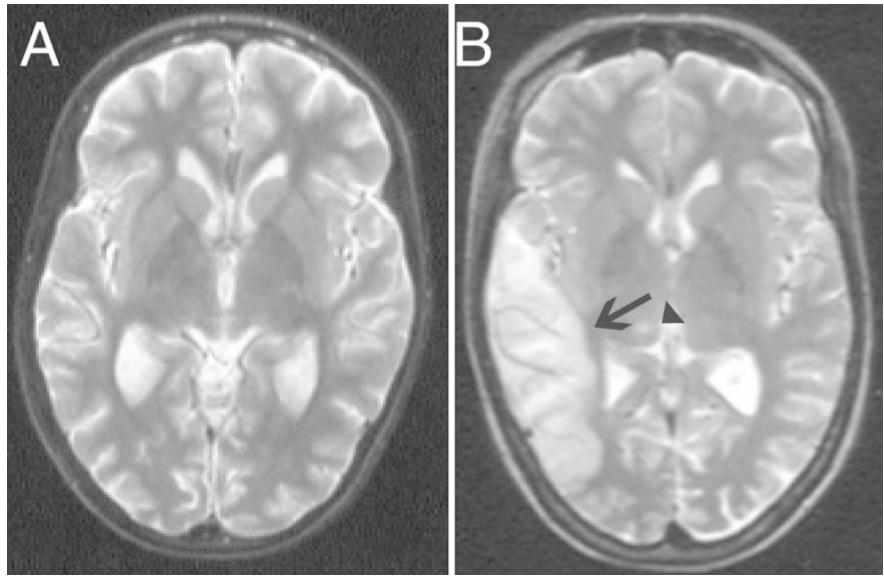

Figure 2. (A) A T2-weighted axial magnetic resonance image at the level of the basal ganglia shows moderate central and cortical atrophy at the age of $13 \mathrm{y}$. (B) A repeated study at the age of $17 \mathrm{y}$ shows widespread cortical and subcortical edema in the right temporoparietal region (arrow) and a small lesion in the right thalamus (arrowhead).

recover and returned home after the 3-wk hospitalization. She had developed contractions in her elbows and ankles during hospitalization but was able to return to her normal school.

She was evaluated by an endocrinologist at the age of $13 \mathrm{y}$. In the arginine, insulin, and adrenocorticotropic hormone stimulation test, her cortisol values were normal and growth hormone values were $1.7,1.5,1.4,5.6,7.2$, and $\mathrm{mg} / \mathrm{L}$, showing partial growth hormone deficiency. Her FSH and LH responses were prepubertal.

Her relative growth began to increase at the age of $13 \mathrm{y}$, and she had menarche at the age of 16 . Two months before death at the age of 18, she had an increasing number of therapyresistant partial seizures without loss of consciousness, which resulted in a stroke-like lesion in the right temporoparietal region and a small lesion in the right thalamus (Fig. 2B). She died of uncontrolled seizures leading to multiorgan failure. The patient did not have diabetes or migraine. Her hearing was normal, and she did not have ptosis, ophthalmoplegia or retinal changes.

Morphologic analysis. Two muscle biopsy samples, taken at the age of $10 \mathrm{y}$, showed a large amount of RRF with variation of fiber size and increased connective tissue. Electron microscopic studies of the muscle biopsy specimen showed enlarged mitochondria with dense granular inclusions and abnormal cristae (Fig. 3). Cachexy and slightly enlarged thyroid gland were noted at autopsy. Neuropathologic investigation of the brain revealed a patchy laminar cortical necrosis that did not follow a typical watershed distribution (Fig. 4). Subcortical pathology was very mild. The findings were consistent with MELAS.

Biochemical and mtDNA analysis. A clear complex I deficiency, with the residual activity of 1.7\% for complex I and $40 \%$ for complex IV were noted (Table 1). In molecular genetic studies, no common mtDNA deletions were found, and the point mutation analyses for MERRF (A8344G) and MELAS (A3243G) were negative. A $\mathrm{T}$ to $\mathrm{C}$ transition mutation at np 3271 was found in $90 \%$ of her fibroblasts with the solid-phase minisequencing technique. The amount of mutated mtDNA in the patient's muscle was found to be $94 \%$. Table 2 lists the quantitative analysis of

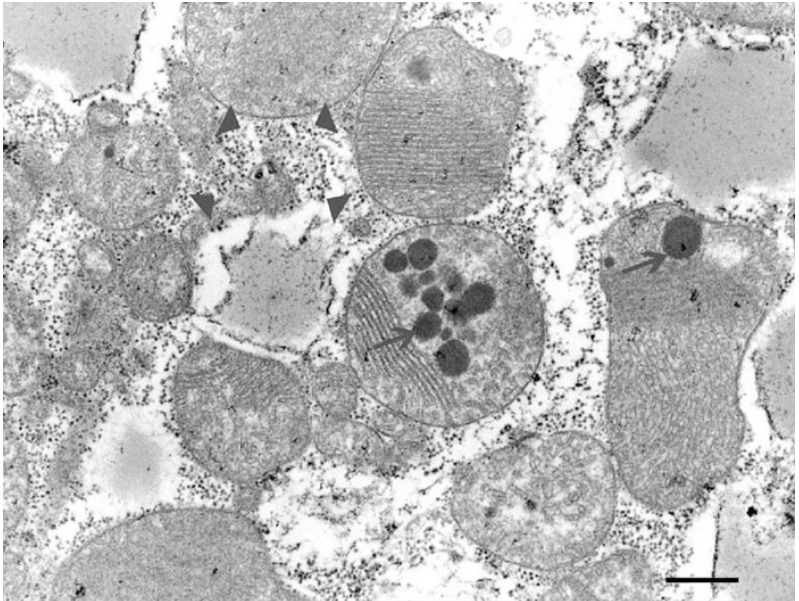

Figure 3. Electron microscopic image of the muscle. Enlarged mitochondria with dense granular inclusions (arrows) and abnormal cristae as well as abundant glycogen granules (between arrowheads) between the mitochondria can be seen. Bar $=200 \mathrm{~nm}$. Magnification: $\times 28,900$.
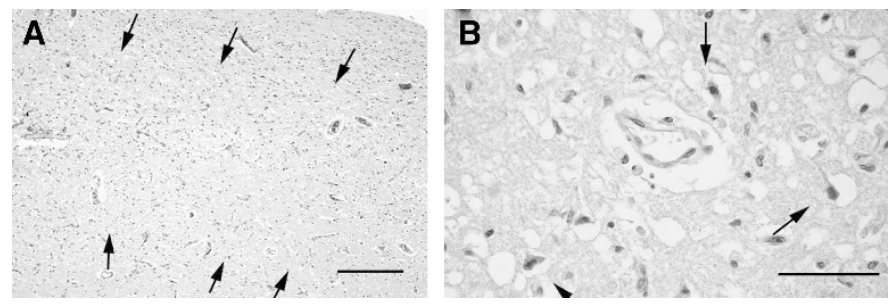

Figure 4. Neuropathology of the brain. (A) Midcortical laminae show incipient necrosis (between arrows) with edema, capillary prominence and dropout of neurons. (B) In high-power view of affected cortex, ischemic "red neurons" (arrows), prominent capillaries, some macrophages, and edema can be observed. Bar $=500 \mu \mathrm{m}$ in $A ; 100 \mu \mathrm{m}$ in $B$.

Table 1. Respiratory chain enzyme analysis of the patient's muscle sample

\begin{tabular}{lrlrcc}
\hline & \multicolumn{3}{c}{ Respiratory chain enzyme analysis } & \\
\cline { 2 - 4 } & $\begin{array}{c}\text { Patient } \\
\text { nmol/min } \\
\mathrm{mg}\end{array}$ & vs. CS & $\begin{array}{c}\text { Controls/n } \\
\text { nmol/min } \\
\mathrm{mg}\end{array}$ & $\begin{array}{c}\text { Relative enzyme } \\
\text { activities, patient } \\
\text { vs. controls }\end{array}$ \\
\hline CI + III & 6.1 & 0.0056 & $295(32)$ & 0.34 & $1.7 \%$ \\
CII + III & 297.6 & 0.27 & $276(37)$ & 0.32 & $84 \%$ \\
CII & 134.5 & 0.12 & $181(16)$ & 0.21 & $57 \%$ \\
CIV & 1318.5 & 1.21 & $2620(10)$ & 3.0 & $40 \%$ \\
CS & 1085.7 & & $858(40)$ & & \\
\hline
\end{tabular}

mutant mtDNA in different autopsy-derived paraffin-embedded tissues of the patient. The amount of mutated mtDNA varied between 78 and 94\%. The T3271C mutation was found in 5, 27, and $4 \%$ of blood leucocytes of the patient's mother and the two younger sisters, respectively.

\section{DISCUSSION}

We report here a juvenile patient with MELAS and the T3271C transition mutation at mitochondrial tRNALeu, which rarely has been reported outside Japan. The symptoms of our patient differed from the other reported patients, because the disease manifested early in life in our patient and the symptoms and signs typical for MELAS did not appear until shortly 
Table 2. The amount of mutated T3271C mtDNA in different tissues quantified by minisequencing. The percentages are means of separate measurements

\begin{tabular}{lc}
\hline \multicolumn{1}{c}{ Tissue } & Percent of mutant mtDNA, \% \\
\hline Adrenal gland & 87 \\
Brain & 85 \\
Fibroblast (DNA) & 94 \\
Heart & 92 \\
Kidney & 89 \\
Liver & 89 \\
Lung & 78 \\
Myoblast (DNA) & 94 \\
Ovary & 88 \\
Small bowel & 91 \\
Spleen & 80 \\
Thyroid & 94 \\
\hline
\end{tabular}

before her death. Her presenting symptoms-poor growth and weight gain and exercise intolerance-are typical for mitochondrial diseases in general. None of her subsequent symptoms - cardiac arrhythmia, cysts in the thyroid gland, or delayed puberty - pointed to any specific mitochondrial entity.

Cardiomyopathy has been reported in $20 \%$ of patients with MELAS and the A3243G mutation but so far in none with the T3271C mutation (23), including our patient. It is interesting that our patient showed delayed sexual development and partial growth hormone deficiency, occasionally also associated with A3243G mutation (24-26).

We recently reported delayed puberty and secondary amenorrhea associated with another mitochondrial disease, progressive external ophthalmoplegia, caused by mutations in the nuclear encoded mtDNA polymerase gamma and multiple mtDNA deletions (26a). Furthermore, increased mtDNA mutations in mice were recently associated with amenorrhea in female mice (27). Further studies should clarify the role of mitochondrial dysfunction in primary ovarian failure.

Seven to $15 \%$ of patients with MELAS are known to have the T3271C mutation, which has been reported to manifest at later age than the most common mutation, the A3243G. The variation of clinical presentation of mtDNA mutations is well illustrated in this family, varying from diabetes to encephalopathy and schizophrenia. Altered mental status and schizophrenia are now known sometimes to precede or accompany the stroke-like episodes in patients with MELAS $(28,29)$. Therefore, it is likely that the psychiatric symptoms of the maternal grandmother were caused by the same $\mathrm{T} 3271 \mathrm{C}$ mutation. In the younger sister, diabetes was the only manifestation. Tarnopolsky et al. (4) found no correlation between the clinical phenotype and the amount of mutant mtDNA in his patients with the T3271C mutation, but such correlation has been found in patients with MELAS and the A3243G mutation (30). In patients with A3243G mutation, the amount of mutant mtDNA in the muscle has a stronger correlation with the clinical phenotype than the amount of mutant mtDNA in the blood leucocytes. The amount of mutant mtDNA in the muscle possibly represents the original mutation load, whereas in the leucocytes, the rapid turnover of the cells is associated with a decrease of the mutation over the years (31). The connection between mutation load and clinical symptoms has been docu- mented in neurogenic muscle weakness, ataxia, and retinitis pigmentosa (NARP) with T8993C/G mutation, leading to an infantile encephalopathy only, if the proportion of the mutant mtDNA exceeds $90 \%(32,33)$. However, in NARP, the levels of mutant mtDNA are similar in muscle and blood (32). No studies on genotype-phenotype correlation in T3271C MELAS have previously been published. We found a very high mutation load in all tissues of the patient, including the brain, yet she was able to attend high school and function normally until the manifestation of illness simulating encephalitis 2 mo before her death. The high mutation load in the kidneys did not give symptoms at all times, but she developed a transient kidney failure that required dialysis during the catastrophic illness after her efforts to improve her physical condition. Eighty-eight percent mutation load in the ovaries can have a connection with the delayed menarche, but because of the early death of our patient, we can only speculate on the effect of the mutation load to her fertility.

Diabetes is rather common with the A3243G MELAS mutation (34). It is surprising that our patient did not have diabetes, but the patient's younger sister, not affected in any other respect, developed diabetes. In the present family, full-blown MELAS developed with $>90 \%$ of mutant mtDNA in most tissues, $30 \%$ of mutant in blood leucocytes resulted in diabetes, and 5\% of mutant did not cause any symptoms. If the grandmother also had T3271C-associated disease, then the manifesting disease jumped over one generation, mimicking recessive inheritance.

Patients with mitochondrial disorders, especially those with mtDNA deletions, may be advised to do physical exercise to improve their condition (35). This report emphasizes that although exercise may be beneficial for a subgroup of patients with mitochondrial disorders, in the case of this patient, exercise was life-threatening. Therefore, exercise recommendations to patients warrant a word of caution.

\section{REFERENCES}

1. Pavlakis SG, Phillips PC, DiMauro S, De Vivo DC, Rowland LP 1984 Mitochondrial myopathy, encephalopathy, lactic acidosis, and strokelike episodes: a distinctive clinical syndrome. Ann Neurol 16:481-488

2. Goto Y, Nonaka I, Horai S 1990 A mutation in the tRNA(Leu)(UUR) gene associated with the MELAS subgroup of mitochondrial encephalomyopathies. Nature 348:651653

3. Kobayashi Y, Momoi MY, Tominaga K, Momoi T, Nihei K, Yanagisawa M, Kagawa Y, Ohta S 1990 A point mutation in the mitochondrial tRNA(Leu)(UUR) gene in MELAS (mitochondrial myopathy, encephalopathy, lactic acidosis and stroke-like episodes). Biochem Biophys Res Commun 173:816-822

4. Tarnopolsky MA, Maguire J, Myint T, Applegarth D, Robinson BH 1998 Clinical, physiological, and histological features in a kindred with the T3271C melas mutation. Muscle Nerve 21:25-33

5. Goto Y, Nonaka I, Horai S 1991 A new mtDNA mutation associated with mitochondrial myopathy, encephalopathy, lactic acidosis and stroke-like episodes (MELAS). Biochim Biophys Acta 1097:238-240

6. Tokunaga M, Mita S, Sakuta R, Nonaka I, Araki S 1993 Increased mitochondrial DNA in blood vessels and ragged-red fibers in mitochondrial myopathy, encephalopathy, lactic acidosis, and stroke-like episodes (MELAS). Ann Neurol 33:275-280

7. Sakuta R, Goto Y, Horai S, Nonaka I 1993 Mitochondrial DNA mutations at nucleotide positions 3243 and 3271 in mitochondrial myopathy, encephalopathy, lactic acidosis, and stroke-like episodes: a comparative study. J Neurol Sci 115:158-160

8. Yanagawa T, Sakaguchi H, Nakao T, Sasaki H, Matsumoto G, Sanke T, Nanjo K 1998 Mitochondrial myopathy, encephalopathy, lactic acidosis, and stroke-like episodes with deterioration during pregnancy. Intern Med 37:780-783

9. Takeda A, Chiba S, Takaaki I, Tanamura A, Yamaguchi Y, Takeda N 1998 Cell cycle of myocytes of cardiac and skeletal muscle in mitochondrial myopathy. Jpn Circ J 62:695-699

10. Shinde A, Nakano S, Taguchi Y, Kagawa D, Akiguchi I 2000 A patient of MELAS with 3271 mutation with fatal outcome after alcohol intake. Rinsho Shinkeigaku 40:561-565 
11. Majamaa K, Moilanen JS, Uimonen S, Remes AM, Salmela PI, Karppa M, MajamaaVoltti KA, Rusanen H, Sorri M, Peuhkurinen KJ, Hassinen IE 1998 Epidemiology of A3243G, the mutation for mitochondrial encephalomyopathy, lactic acidosis, and strokelike episodes: prevalence of the mutation in an adult population. Am J Hum Genet 63:447-454

12. Chinnery PF, Johnson MA, Wardell TM, Singh-Kler R, Hayes C, Brown DT, Taylor RW, Bindoff LA, Turnbull DM 2000 The epidemiology of pathogenic mitochondrial DNA mutations. Ann Neurol 48:188-193

13. Ciafaloni E, Ricci E, Shanske S, Moraes CT, Silvestri G, Hirano M, Simonetti S, Angelini C, Donati MA, Garcia C, Martinuzzi A, Mosewich R, Servidei S, Zammarchi E, Bonilla E, DeVivo DC, Rowland LP, Schon E, DiMauro S 1992 MELAS: clinical features, biochemistry, and molecular genetics. Ann Neurol 31:391-398

14. van den Ouweland JM, Lemkes HH, Ruitenbeek W, Sandkuijl LA, de Vijlder MF, Struyvenberg PA, van de Kamp JJ, Maassen JA 1992 Mutation in mitochondrial tRNA(Leu)(UUR) gene in a large pedigree with maternally transmitted type II diabetes mellitus and deafness. Nat Genet 1:368-371

15. Moraes CT, Ciacci F, Silvestri G, Shanske S, Sciacco M, Hirano M, Schon EA, Bonilla E, DiMauro S 1993 Atypical clinical presentations associated with the MELAS mutation at position 3243 of human mitochondrial DNA. Neuromuscul Disord 3:43-50

16. Hammans SR, Sweeney MG, Hanna MG, Brockington M, Morgan-Hughes JA, Harding AE 1995 The mitochondrial DNA transfer RNALeu(UUR) A->G(3243) mutation. A clinical and genetic study. Brain 118:721-734

17. Morgan-Hughes JA, Sweeney MG, Cooper JM, Hammans SR, Brockington M, Schapira AH, Harding AE, Clark JB 1995 Mitochondrial DNA (mtDNA) diseases: correlation of genotype to phenotype. Biochim Biophys Acta 1271:135-140

18. van den Ouweland JM, Maechler P, Wollheim CB, Attardi G, Maassen JA 1999 Functional and morphological abnormalities of mitochondria harbouring the tRNA(L$\mathrm{eu}$ (UUR) mutation in mitochondrial DNA derived from patients with maternally inherited diabetes and deafness (MIDD) and progressive kidney disease. Diabetologia 42:485-492

19. Majander A, Rapola J, Sariola H, Suomalainen A, Pohjavuori M, Pihko H 1995 Diagnosis of fatal infantile defects of the mitochondrial respiratory chain: age dependence and postmortem analysis of enzyme activities. J Neurol Sci 134:95-102

20. Suomalainen A, Majander A, Haltia M, Somer H, Lonnqvist J, Savontaus ML, Peltonen L 1992 Multiple deletions of mitochondrial DNA in several tissues of a patient with severe retarded depression and familial progressive external ophthalmoplegia. J Clin Invest 90:61-66

21. Suomalainen A, Majander A, Pihko H, Peltonen L, Syvanen AC 1993 Quantification of tRNA3243(Leu) point mutation of mitochondrial DNA in MELAS patients and its effects on mitochondrial transcription. Hum Mol Genet 2:525-534

22. Shibata DK, Arnheim N, Martin WJ 1988 Detection of human papilloma virus in paraffin-embedded tissue using the polymerase chain reaction. J Exp Med 167:225-230
23. Silvestri G, Bertini E, Servidei S, Rana M, Zachara E, Ricci E, Tonali P 1997 Maternally inherited cardiomyopathy: a new phenotype associated with the A to G AT nt. 3243 of mitochondrial DNA (MELAS mutation). Muscle Nerve 20:221-225 24. Huang CC, Chen RS, Chen CM, Wang HS, Lee CC, Pang CY, Hsu HS, Lee HC, Wei YH 1994 MELAS syndrome with mitochondrial tRNA(Leu(UUR)) gene mutation in a Chinese family. J Neurol Neurosurg Psychiatry 57:586-589

25. Chen CM, Huang CC 1995 Gonadal dysfunction in mitochondrial encephalomyopathies. Eur Neurol 35:281-286. (MELAS mutation). Muscle Nerve 20:221-225

26. Balestri P, Grosso S 2000 Endocrine disorders in two sisters affected by MELAS syndrome. J Child Neurol 15:755-758

26a.Luoma P, Mehlberg A, Rinnhe JO, Kaukonen JA, Nupponen NN, Chalmers RM, Oldfors A, Rautakorpi I, Peltonen L, Majamaa K, Somer H, Suomalinen A 2004 Parkinsonism, premature menopause, and mitochondrial DNA polymerase gamma mutations: clinical and molecular genetic study. Lancet 364:875-882

27. Trifunovic A, Wredenberg A, Falkenberg M, Spelbrink JN, Rovio AT, Bruder CE, Bohlooly YM, Gidlof S, Oldfors A, Wibom R, Tornell J, Jacobs HT, Larsson NG 2004 Premature ageing in mice expressing defective mitochondrial DNA polymerase. Nature 429:417-423

28. Suzuki T, Koizumi J, Shiraishi H, Ishikawa N, Ofuku K, Sasaki M, Hori T, Ohkoshi N, Anno I 1990 Mitochondrial encephalomyopathy (MELAS) with mental disorder. CT, MRI and SPECT findings. Neuroradiology 32:74-76

29. Thomeer EC, Verhoeven WM, van de Vlasakker CJ, Klompenhouwer JL 1998 Psychiatric symptoms in MELAS; a case report. J Neurol Neurosurg Psychiatry 64:692-693

30. Chinnery PF, Howell N, Lightowlers RN, Turnbull DM 1997 Molecular pathology of MELAS and MERRF. The relationship between mutation load and clinical phenotypes. Brain 120:1713-1721

31. Rahman S, Poulton J, Marchington D, Suomalainen A 2001 Decrease of 3243 A->G mtDNA mutation from blood in MELAS syndrome: a longitudinal study. Am J Hum Genet 68:238-240

32. Makela-Bengs P, Suomalainen A, Majander A, Rapola J, Kalimo H, Nuutila A, Pihko H 1995 Correlation between the clinical symptoms and the proportion of mitochondrial DNA carrying the 8993 point mutation in the NARP syndrome. Pediatr Res 37:634-639

33. Silvestri G, Ciafaloni E, Santorelli FM, Shanske S, Servidei S, Graf WD, Sumi M, DiMauro S 1993 Clinical features associated with the A-> G transition at nucleotide 8344 of mtDNA ("MERRF mutation"). Neurology 43:1200-1206

34. van den Ouweland JM, Lemkes HH, Gerbitz KD, Maassen JA 1995 Maternally inherited diabetes and deafness (MIDD): a distinct subtype of diabetes associated with a mitochondrial tRNA(Leu)(UUR) gene point mutation. Muscle Nerve 3:S124-130

35. Taivassalo T, Shoubridge EA, Chen J, Kennaway NG, DiMauro S, Arnold DL, Halle RG 2001 Aerobic conditioning in patients with mitochondrial myopathies: physiological, biochemical, and genetic effects. Ann Neurol 50:133-141 